\title{
SEISMIC COMPARATIVE STUDY ON TMD STRUCTURE: AN OVERVIEW
}

\author{
Paramanna B Patil ${ }^{1}$, Chethan Kumar B ${ }^{2}$ \\ ${ }^{1}$ Post Graduate Student, Structural Engineering, VijayaVittala Institute of Technology, Bangalore \\ ${ }^{2}$ Assistant Professor, Structural Engineering, VijayaVittala Institute of Technology, Bangalore
}

\begin{abstract}
In larger context of civil engineering use of mechanical vibration control device is very often in present days, so this paper will provide the successful implementation specification of TMD to reduce the vibration induced due earthquake ground motion, with computer stimulated model \& dynamic responses are obtained for seismic loading with \& without TMD which drastically reduces seismic response such as lateral displacement, story drift, base shear, overturning moment. Even actual behavior study on structure has been carried by inducing ground motion to the structure by considering time history data of El-Centro \& recent earthquake (2014) which happened in India.
\end{abstract}

Keywords: TMD, Time History, Base Shear, Story Drift, El-Centro etc...

\section{INTRODUCTION}

It is interesting to note that the use of active and passive devices is practice since from 1999 in India with first successful installation in killari village after suffering great loss of life and money due to earthquake caused in the year 1993.

The base isolator is very firstly introduced in killari village for the single story building. Coincidently building is located very near to the location ofKillari Earthquake epicenter.Again second application is done to hospital building by learning lesson after great loses in life from 2001 Bhuj earthquake in Gujarat. All though there is no section related to analysis, design implementation provisions are not available in IS codes except some special draft prepared by GSDMA. So this paper made an attempt to study how the energy absorbing device (TMD) can perform during earthquake.

\section{BUILDING DESCRIPTION}

Symmetrical plan building $(\mathrm{G}+4)$ has been considered for the present study, Design has been carried for the vertical load combination, which is having 2 bay along both $X \& Y$ axis along with $6 \mathrm{~m}$ spacing in each grid, story height of $3 \mathrm{~m}$, grade of concrete $=\mathrm{M} 25$, poisons ratio as 0.15 .

Numerical Formulation TMD:TMD can be modeled as spring mass system with three primary elements; a mass, a spring \& a damper. Several authors has given the numerical stimulation technique in which Prof.Hartog's (1947) made remarkable mathematical formulation which is well known and it was adopted all over with certain limitations.

\section{EARTHQUAKE TIME HISTORY}

Earthquake time history file includes information such as origin time of earthquake which happened on that particular station where we are recording responses along with longitude, latitude, magnitude, station height, depth, site classification based on shear wave velocity, maximum acceleration, duration of time, sampling rate. Usually acceleration data of Indian earthquake will be measured in terms of $\mathrm{cm} / \mathrm{sec} 2$. Some of the researchers are interested to converter this data in terms of acceleration due to gravity (g) i.e. $0.2 \mathrm{~g}, 0.3 \mathrm{~g}, 0.4 \mathrm{~g}$ by amplifying recorded ground motion. Table 1 gives some insight knowledge into the ground motion data study.

Table-1: Time History Data File Information.

\begin{tabular}{|l|l|l|}
\hline Latitude & $27.6 \mathrm{~N}$ & $28.6 \mathrm{~N}$ \\
\hline Longitude & $76.7 \mathrm{E}$ & $77.0 \mathrm{E}$ \\
\hline Depth (Km) & 13 & 20.3 \\
\hline Magnitude & 3.9 & 4.3 \\
\hline Region & $\begin{array}{l}\text { ALWAR- } \\
\text { RAJASTHAN }\end{array}$ & $\begin{array}{l}\text { DELHI- } \\
\text { HARYANA- } \\
\text { BORDER- } \\
\text { REGION }\end{array}$ \\
\hline Station Code & ALW & REW \\
\hline $\begin{array}{l}\text { Station } \\
\text { Height(m) }\end{array}$ & 289 & 246 \\
\hline Site Class & A & C \\
\hline Record Time & 29.11 .2006 & $\begin{array}{l}25.11 .2007 \\
05: 41: 05.554\end{array}$ \\
\hline Sampling Rate & $200 . \mathrm{Hz}$ & $200 . \mathrm{Hz}$ \\
\hline $\begin{array}{l}\text { Record } \\
\text { Duration }\end{array}$ & $31.130 \mathrm{Sec}$. & $33.530 \mathrm{Sec}$. \\
\hline Direction & Vertical & Vertical \\
\hline $\begin{array}{l}\text { Max. } \\
\text { Acceleration( } \\
\text { cm/sec2) }\end{array}$ & 51.705 & -12.246 \\
\hline
\end{tabular}




\section{TIME HISTORY ANALYSIS}

Time history analysis belongs to dynamic analysis. Time history analysis is performed by privies model analysis result by model superposition or by direct integration techniques with each increment in time step .Model superposition type can used to perform FNA in computer simulated model which requires very less disk space whereas Direct integration method is little cumbersome in case of time and requires very large disk space and time. So time history analysis kept away for usual daily design practice and restricted to research works.

\section{RESULTS}

Strictly speaking with sound knowledge of experiment data of devices, earthquake engineer should demonstrate detailed analysis and design with acceptable performance values of device. Then only a tuned mass damper or energy observing device can be used in earthquake resistant design.

TMD shows remarkable impact of use of passivemechanical damping methods

\subsection{Lateral Displacement}

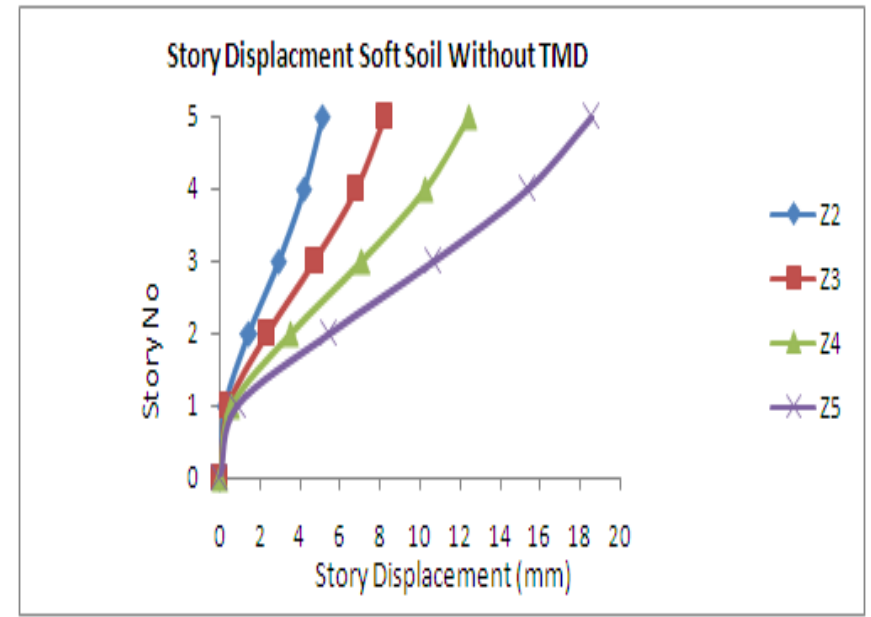

Chart -1: Zonal compression of lateral displacement for without TMD in soft soil

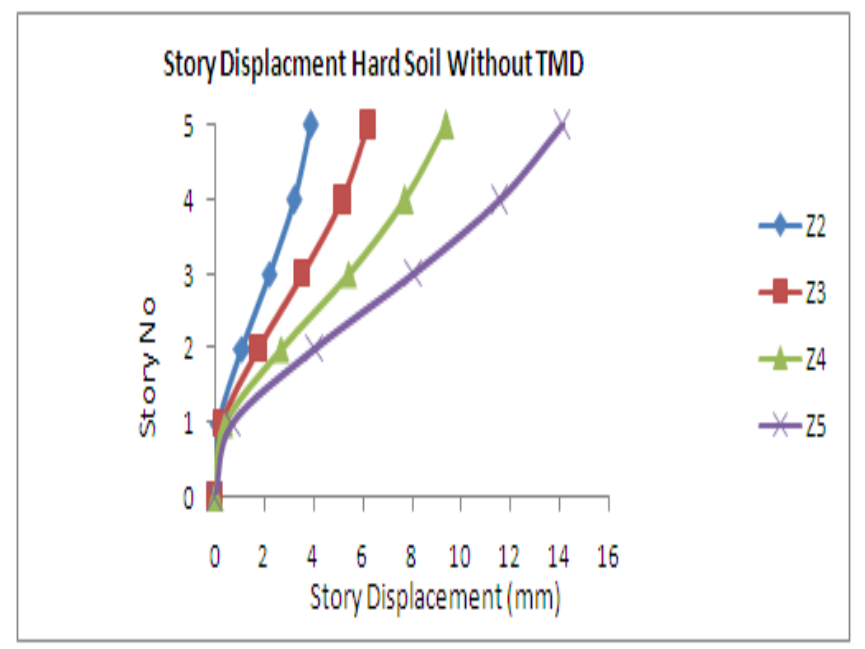

Chart -2: Zonal compression of lateral displacement for without TMD in hard soil

\section{Story Displacment Soft Soil With TMD}

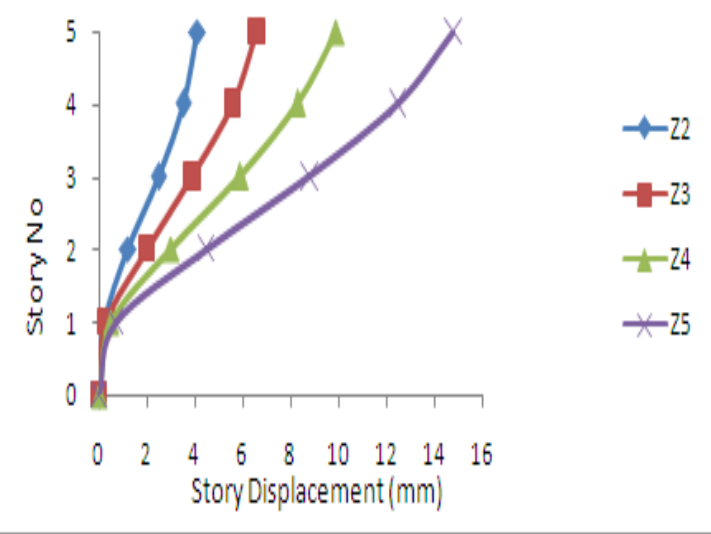

Chart -3: Zonal compression of lateral displacement for with TMD in soft soil

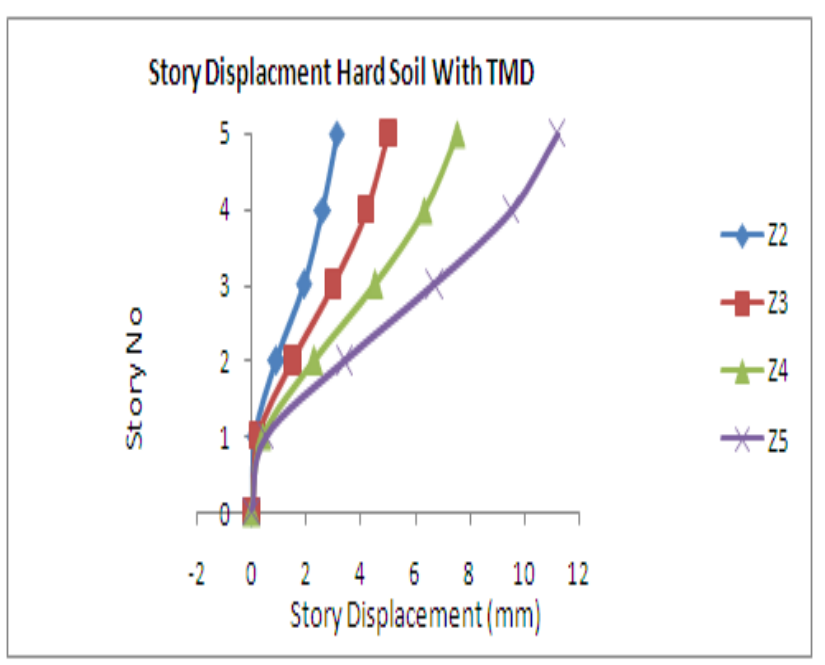

Chart -4: Zonal compression of lateral displacement for with TMD in hard soil

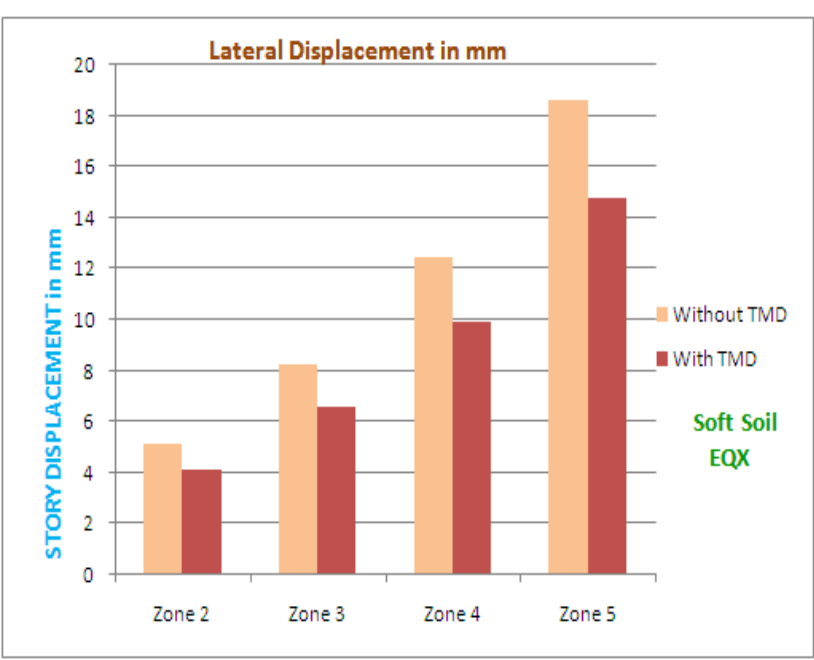

Chart -5: Compression of lateral displacement for with \& without TMD in soft soil 


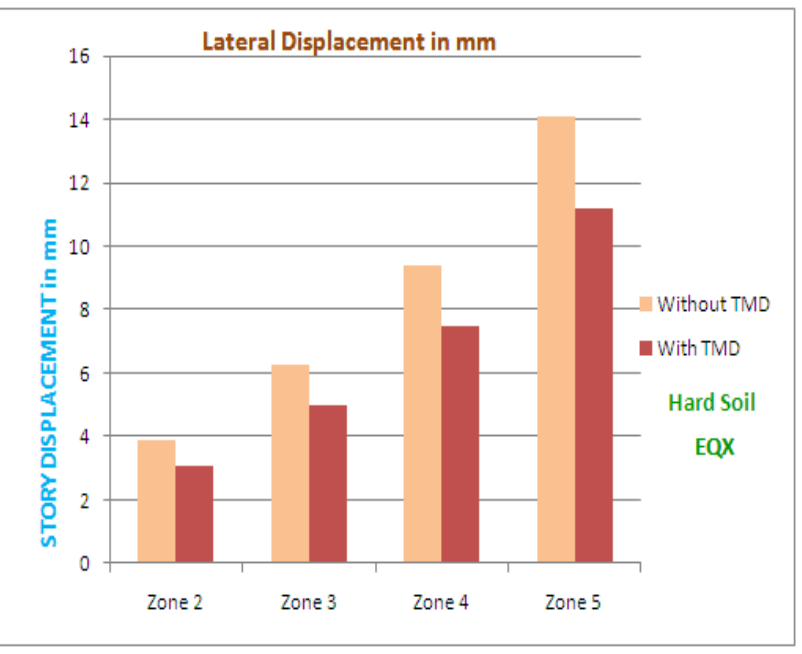

Chart -6: Compression of lateral displacement for with \& without TMD in hard soil

\subsection{Story Drift}

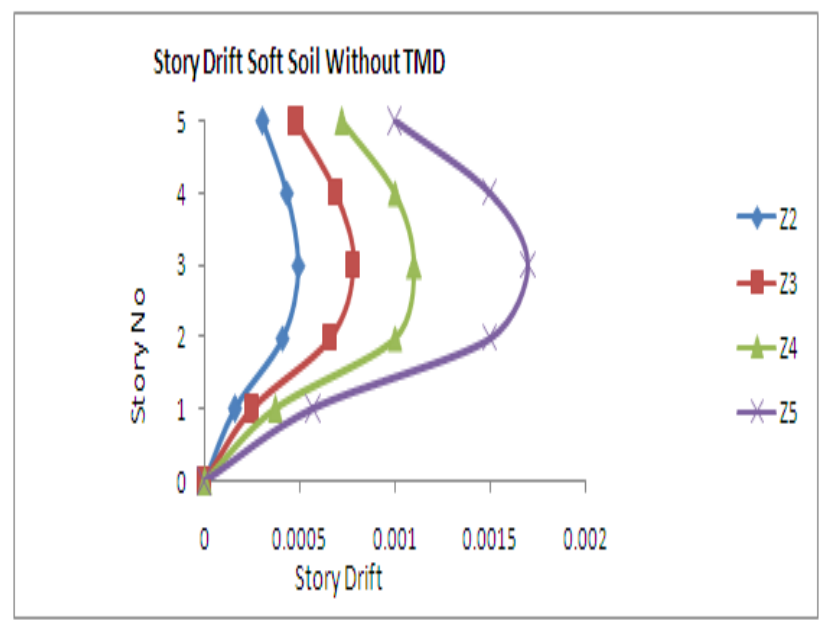

Chart -7: Zonal compression of Story Drift for without TMD in soft soil

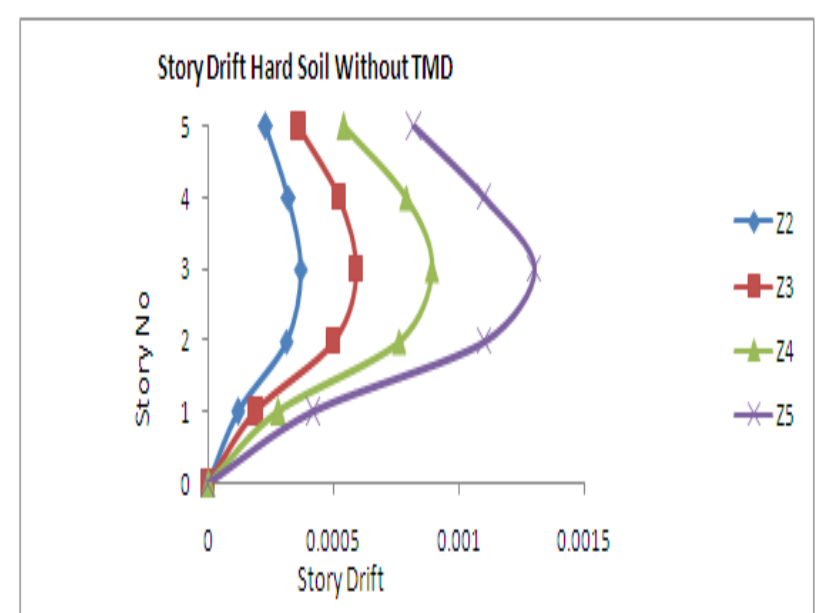

Chart -8: Zonal compression of Story Drift for without TMD in hard soil

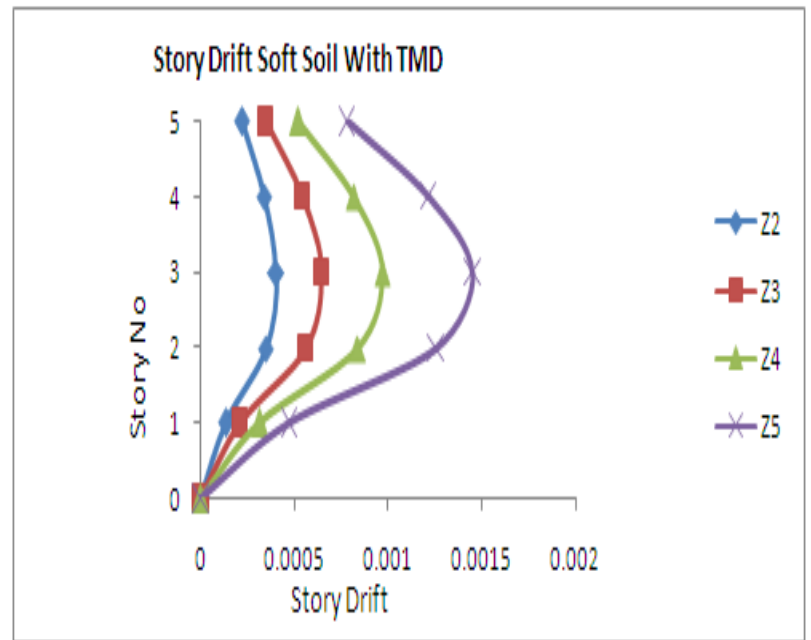

Chart -9: Zonal compression of Story Drift for with TMD in soft soil

\section{StoryDrift Hard Soil With TMD}

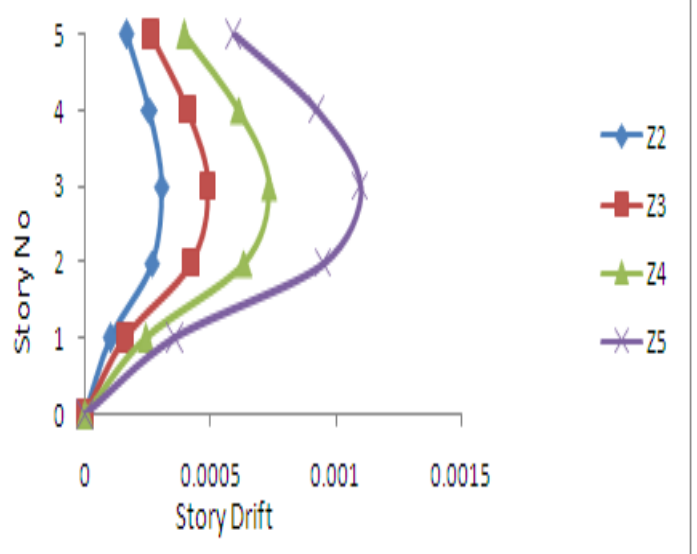

Chart -10: Zonal compression of Story Drift for with TMD in hard soil

\subsection{Story Shear}

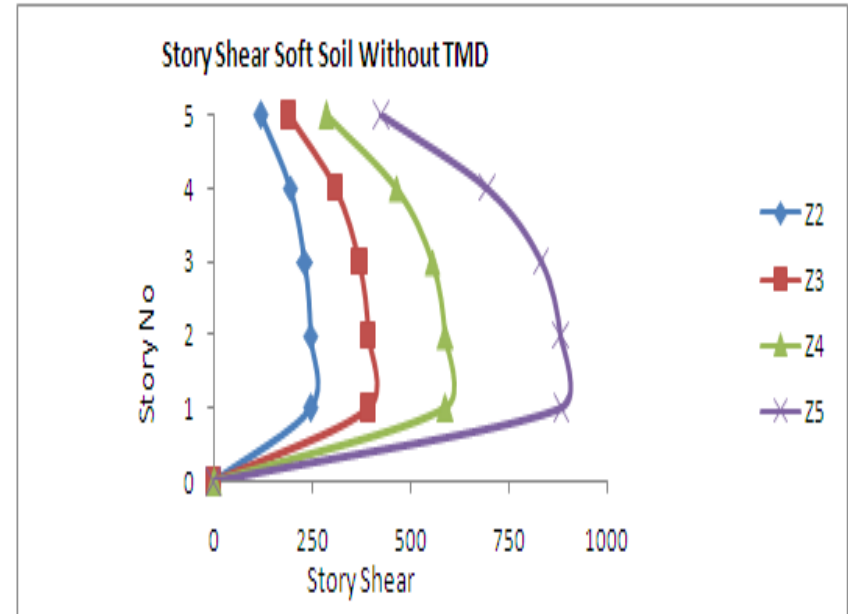

Chart -11: Zonal compression of Story Shear for without TMD in soft soil 


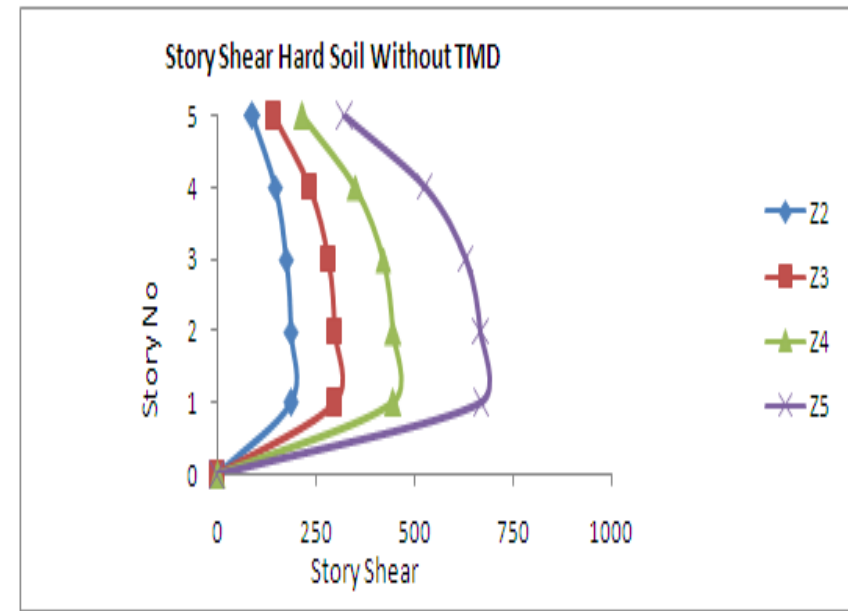

Chart -12: Zonal compression of Story Shear for without TMD in hard soil

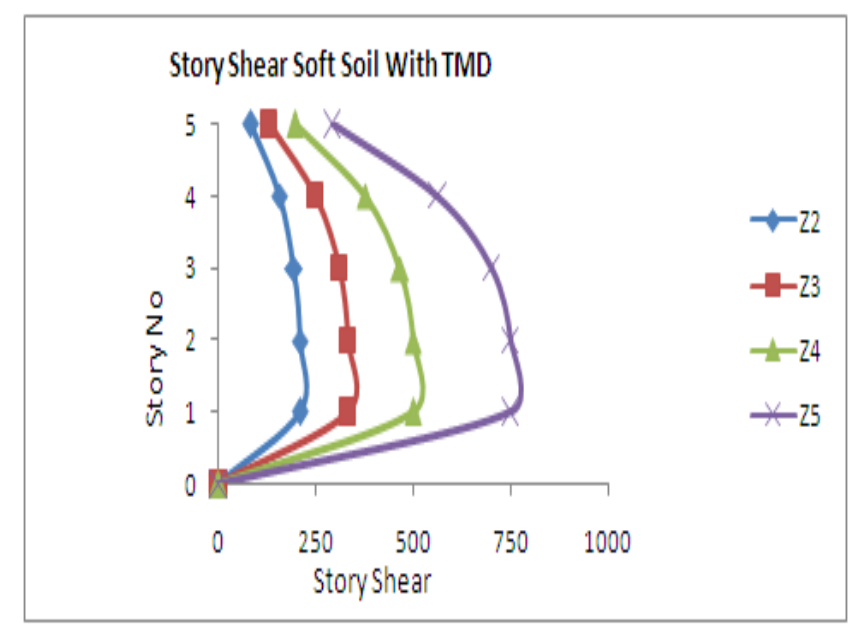

Chart -13: Zonal compression of Story Shear for with TMD in soft soil

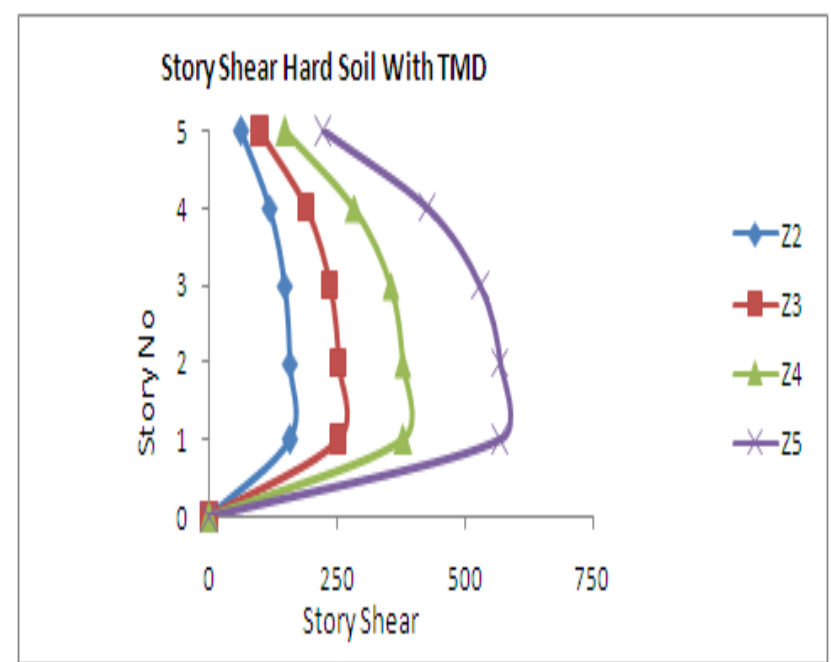

Chart -14: Zonal compression of Story Shear for with TMD in hard soil

\subsection{Overturning Moment}

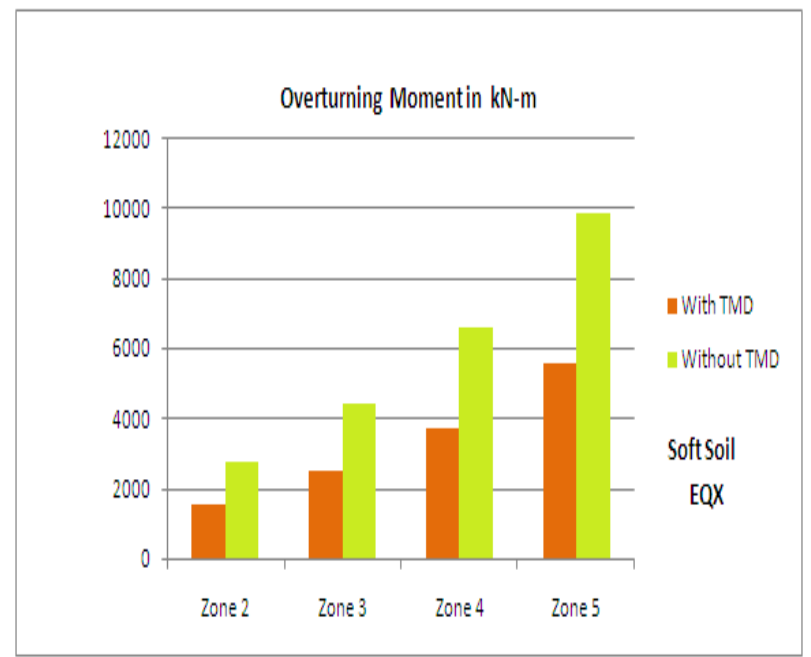

Chart -15: Compression of overturning moment for with \& without TMD in soft soil

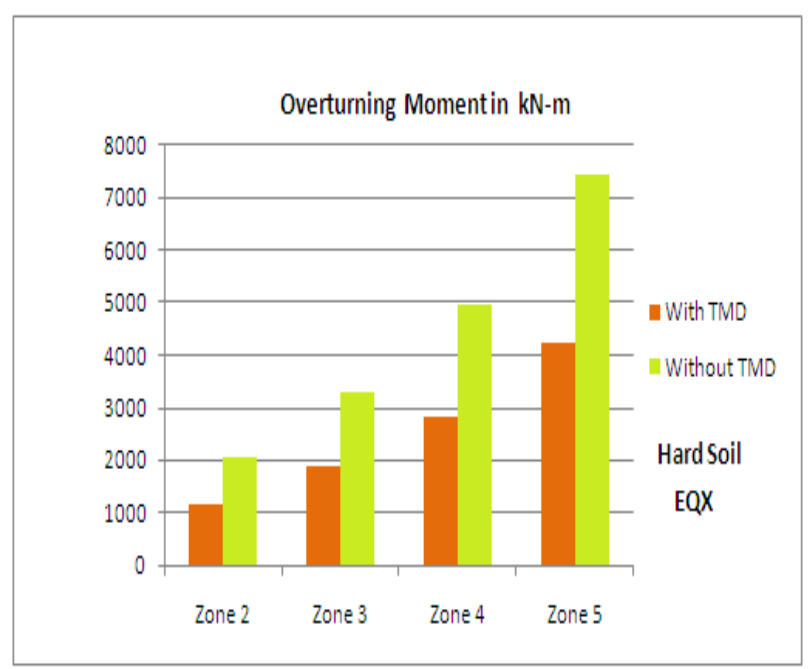

Chart -16: Compression of overturning moment for with \& without TMD in hard soil

\subsection{Time History Analysis}

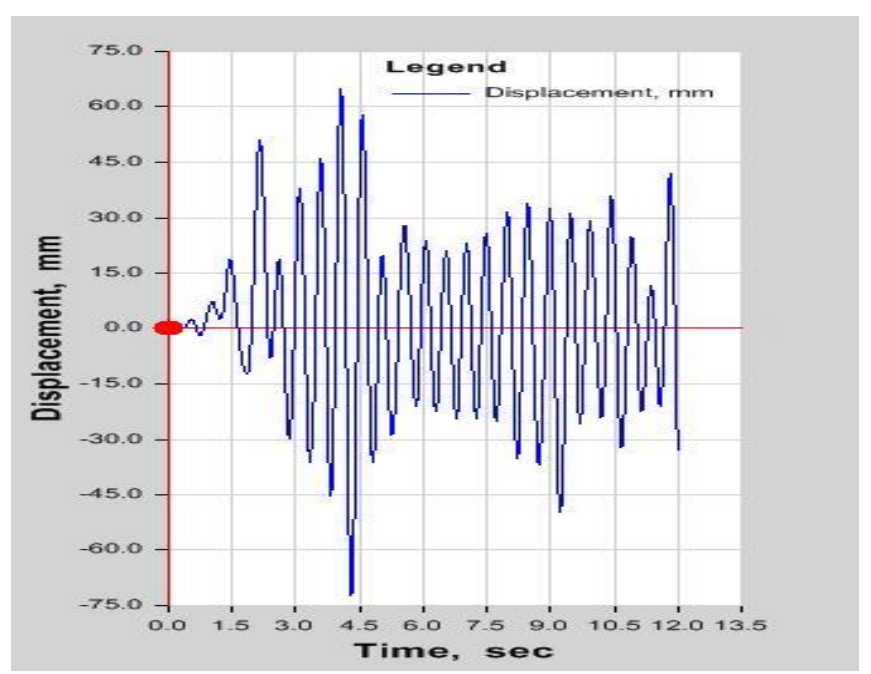

Chart -17: Roof displacement @ story 4 for with TMD in El-Centro Ground motion 


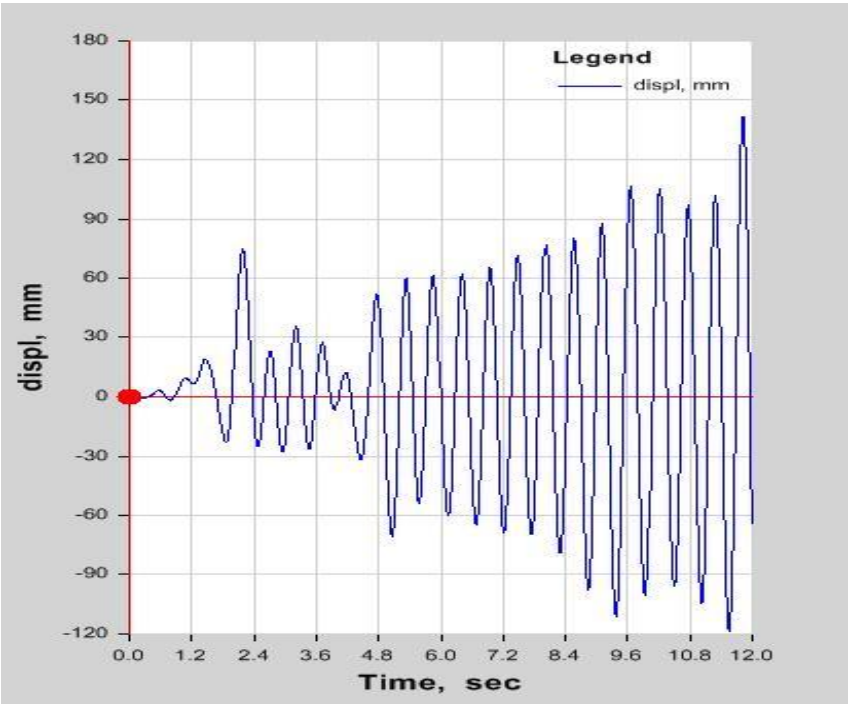

Chart -18: Roof displacement @ story 4 for without TMD in El-Centro Ground motion

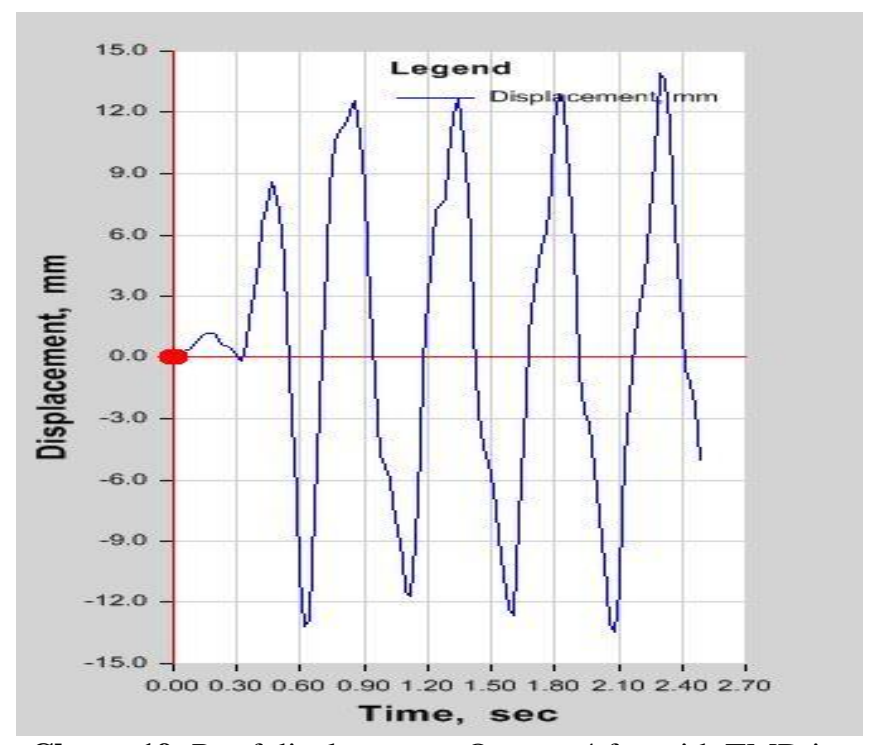

Chart -19: Roof displacement @ story 4 for with TMD in Yermo Ground motion

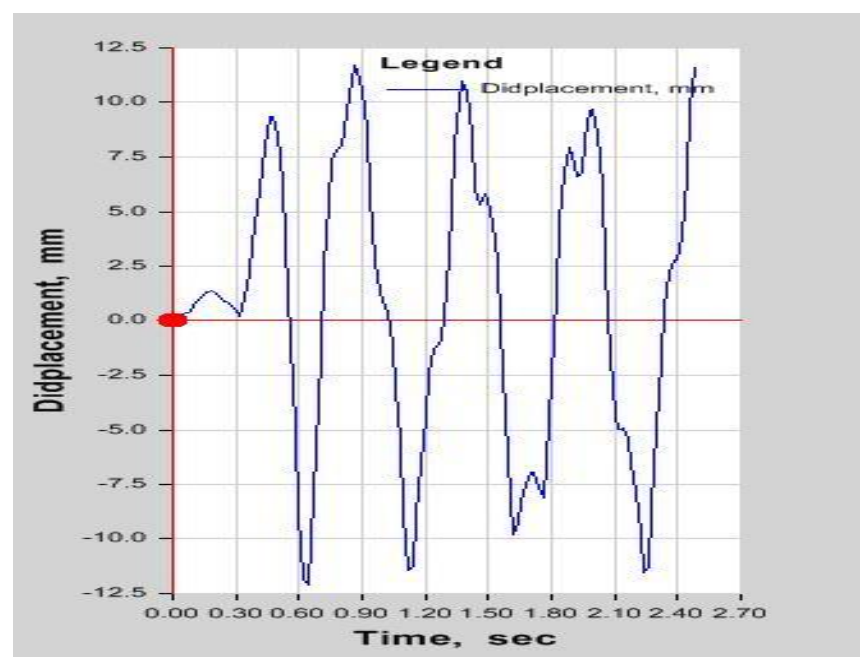

Chart -20: Roof displacement @ story 4 for without TMD in Yermo Ground motion

\section{CONCLUSION}

As in the study we considered lateral resisting system which are most essential in case of lifeline structure or major structures such as hospital and nuclear power station, which illustrates that more the number in combination of lateral resisting systems, the less in global collapse mechanism.

1) It'sclear from above chart's that there is an cumulative increases in the values of story drift, Lateral displacement, Story shear \& overturning moment in the order of zone 2 to zone 5 with hard soil to soft soil.

2) Implementation of TMD system results into reduction in story drift, story shear, lateral displacement, overturning moment. This reduction enables the structure to behave as almost stiff. In this way we can reduce localized damage of nonstructural \& structural elements.

\section{REFERENCES}

[1] Masato Abe. "Semi-Active Tuned Mass Dampers with Pulse Control", Eleventh World Conference on Earthquake Engineering, Paper ID-8, Pp. No-1-8, 1996.

[2] Hyung-Oh Kwon, Min-Ki Jeong, Doo-Hoon Kim. "An Experimental Study of the Dynamic Characteristics of Viscous Fluid Dampers for Base Isolated Building", $12^{\text {th }}$ World Conference on Earthquake Engineering, Paper ID-2440, Pp. No-16, 2000, Japan.

[3] Cedric Marsh. "The Control of Building Motion by Friction Dampers", $12^{\text {th }}$ World Conference on Earthquake Engineering, Paper ID-63, Pp. No-1-6, 2000, Japan.

[4] KathuhikoNoyori, Yoshito Maeda, Shinji Aramaki, Kiyoshi Uno. "Hysterisis Characteristic of Lead Pillar Damper", $12^{\text {th }}$ World Conference on Earthquake Engineering, Paper ID-332, Pp. No-1-6, 2000, Japan.

[5] Takanori Sato, Takehiko Terada, Tetsuya Hanzawa. "Proposal of Soft-Elastic Building Structure with High Capacity Damper", $12^{\text {th }}$ World Conference on Earthquake Engineering, Paper ID-449, Pp. No-1-6, 2000, Japan.

[6] Kensuke Baba, Yutaka Inoue, Fumiaki Arima, Hidetsugu Kuroda. "Principles and Characteristics of Viscous Damping Devices (Gyro-Damper): The Damping Forces Which are Highly Amplified by Converting the Axial Movement to Rotary One", $12^{\text {th }}$ World Conference on Earthquake Engineering, Paper ID-588, Pp. No-1-7, 2000, Japan.

[7] Mitsuo Sakamoto, Jun Agami, NorihideKoshika, Yasushi Kurokawa, Norio Suzuki, Akihiro Kunisue. "Retrofitting Method of Existing Reinforced Concrete Buildings Using Elasto-Plastic Steel Dampers", $12^{\text {th }}$ World Conference on Earthquake Engineering, Paper ID-648, Pp. No-1-8, 2000, Japan.

[8] Masaaki Tsuji, Koji Uetani, Yasuyuki Nagano, Makoto Ohsaki. "Optimum Design Method for 
High-Rise Building Frame with Viscous Dampers", $12^{\text {th }}$ World Conference on Earthquake Engineering, Paper ID-754, Pp. No-1-8, 2000, Japan.

[9] LuísGuerreiro, Francisco Virtuoso, Joao Azevedo. "Modelling the Seismic Behaviour of Bridges with Viscous Dampers ", $12^{\text {th }}$ World Conference on Earthquake Engineering, Paper ID-782, Pp. No-1-8, 2000, Japan.

[10] Hideaki Ageta, Mitsukazui Nakanishi, KeijiKitajima, Hiromi Adachi. "Research and Development of Response-Control Retrofitting Techniques by Means of Friction Damper", $12^{\text {th }}$ World Conference on Earthquake Engineering, Paper ID-868, Pp. No-1-8, 2000, Japan.

[11] Hideaki Ageta, Mitsukazu Nakanishi, KeijiKitajima, Hiromi Adachi. "Pseudo-Dynamic Test on Reinforced Concrete Frame Retrofitted With Damper ", $12^{\text {th }}$ World Conference on Earthquake Engineering, Paper ID-869, Pp. No-1-8, 2000, Japan.

[12] Chang-Yong Lee, Jinkoo Kim. "Analysis of a NonProportionally Damped Building Structure with Added Viscoelastic Dampers", $12^{\text {th }}$ World Conference on Earthquake Engineering, Paper ID907, Pp. No-1-8, 2000, Japan.

[13] ShigeyaKawamata, Yoshiro Itoh, Naoki Funaki. "Passive Control of Building Frames by Means of Liquid Dampers Sealed by Viscoelastic Material", $12^{\text {th }}$ World Conference on Earthquake Engineering, Paper ID-981, Pp. No-1-8, 2000, Japan.

[14] Tadaki Katayama, Shigeki Ito, HisayaKamura, Takuya Ueki, Haruhito Okamoto. "Experimental Study on Hysteretic Damper with Low Yield Strength Steel under Dynamic Loading", $12^{\text {th }}$

World Conference on Earthquake Engineering, Paper ID-1020, Pp. No-1-8, 2000, Japan.

[15] ImadMualla. "Experimental Evaluation of New Friction Damper Device", $12^{\text {th }}$ World Conference on Earthquake Engineering, Paper ID-1020, Pp. No-17, 2000, Japan.

[16] H Bedair, O Pekau, B Dasgupta, "Improved Deployment of Friction Dampers in Asymmetric Multi-Story Buildings", $12^{\text {th }}$ World Conference on Earthquake Engineering, Paper ID-1144, Pp. No-18, 2000, Japan.

[17] Yuji Takahashi, Satsuya Soda. "Performance Based Seismic Design of Building Structures with Viscoelastic Dampers", $12^{\text {th }}$ World Conference on Earthquake Engineering, Paper ID-1236, Pp. No-18, 2000, Japan.

[18] Kiyoshi Tanaka, Yasuhito Sasaki. "Hysteretic Performance of Shear Panel Dampers of Ultra LowYield-Strength Steel for Seismic Response Control of Buildings", $12^{\text {th }}$ World Conference on Earthquake Engineering, Paper ID-1248, Pp. No-1-8, 2000, Japan.

[19] Hiroyuki Tamai, Kazuo Kondoh, Yoshikazu Kitagawa, Masami Hanai. "Shape Effect on Seismic Energy Absorption Capacity of Hysteretic Damper for K-Braced Frame", $12^{\text {th }}$ World Conference on
Earthquake Engineering, Paper ID-2674, Pp. No-18, 2000, Japan.

[20] Tudor Sireteanu, Charles Stammers. "Dual SemiActive Friction Dampers to Reduce Building Response to Seismic Inputs", $12^{\text {th }}$ World Conference on Earthquake Engineering, Paper ID-2674, Pp. No1-8, 2000, Japan.

[21] William Robinson, Jim Cousins, John Zhao. "Using a Lead-Based Damper to Increase Near-Source Ground Motion Resisting Capacity of Existing Base-Isolated Structures ", $12^{\text {th }} \quad$ World Conference on Earthquake Engineering, Paper ID2561, Pp. No-1-5, 2000, Japan.

[22] Xi Lin, Athol Carr, Peter Moss. "Seismic Analysis and Design of Building Structures with Supplemental Lead Dampers", $12^{\text {th }}$ World Conference on Earthquake Engineering, Paper ID1417, Pp. No-1-8, 2000, Japan.

[23] Yosuke Shimawaki, Hideo Kondo, Seung-Jae Lee, Kenichi Ohi. "Pseudo-Dynamic Tests on Serviceable and Robust Steel Frames with the Combination of Hysteretic Dampers and Semi-Rigid Connections", $12^{\text {th }}$ World Conference on Earthquake Engineering, Paper ID-2300, Pp. No-1-8, 2000, Japan.

[24] Yasuyuki Nagano, I Takewaki, T Okamoto, M Tsuji. "Application of Optimum Design Methods to Actual High-Rise Building with Hysteretic Dampers", 12 ${ }^{\text {th }}$ World Conference on Earthquake Engineering, Paper ID-1463, Pp. No-1-8, 2000, Japan.

[25] Yutaka Ishida, Masayuki Ninomiya, Masato Usami, YasuoTsuyuki, ToshifumiOkuzono, Osamu Takahashi, ShigekatsuIchihasi. "Vibration Test of a Frame which has an Oil-Damper Brace", $12^{\text {th }}$ World Conference on Earthquake Engineering, Paper ID1503, Pp. No-1-8, 2000, Japan.

[26] Higashino Masahiko, Mitsuo Asano, Masashi Yamamoto. "The Experimental Study on Viscoelastic Material Dampers and the Formulation of Analytical Model", $\quad 12^{\text {th }}$ World Conference on Earthquake Engineering, Paper ID-1535, Pp. No1-8, 2000, Japan.

[27] Suwa Hitoshi, Nakamura Takashi, Inaba Satoru, NobataArihide, Suzuki Tetsuo. "Study on Earthquake Response Characteristics of BaseIsolated Building Using the Friction Dampers with Coned Disc Springs", $12^{\text {th }}$ World Conference on Earthquake Engineering, Paper ID-1891, Pp. No-18, 2000, Japan.

[28] Tadashi Nagase. "Earthquake Records Observed in Tall Buildings with Tuned Pendulum Mass Damper", $12^{\text {th }}$ World Conference on Earthquake Engineering, Paper ID-1893, Pp. No-1-8, 2000, Japan.

[29] Yoshihiro Nitta, Akira Nishitani. "Hybrid Structural Control Combining Active Mass Driver and Hysteretic Damper Systems", $12^{\text {th }}$ World Conference on Earthquake Engineering, Paper ID1897, Pp. No-1-8, 2000, Japan. 
[30] YojiIshibashi, Yoshihiro Nitta, Akira Nishitani. "Structural Control Based on Semi-Active Variable Friction Dampers", $12^{\text {th }}$ World Conference on Earthquake Engineering, Paper ID-1897, Pp. No-18, 2000, Japan. 